Brit. Heart f., 1966, 28, 718.

\title{
Congenital Aortic Arch Abnormalities with the "Subclavian-steal" Pattern of Blood Flow
}

\author{
W. G. BRADLEY* \\ From the Postgraduate Medical School, Hammersmith Hospital, London W.12
}

Since Reivich et al. (1961) drew attention to the reversal of flow in a vertebral artery resulting from obstruction of the origin of the ipsilateral subclavian artery, many cases of the so-called "subclaviansteal" syndrome have been reported. In most of these cases the obstruction has been caused by arteriosclerosis or an arteritis. Massumi (1963) reported the case of a boy of 6 years who had the "subclavian-steal" pattern of blood flow from congenital subclavian atresia. A further case of this rare congenital variety is reported below.

\section{Case History}

B.M., a 21-year-old man, was diagnosed as having coarctation of the aorta at the age of 8 years, when he was seen because of enuresis. There was a basal systolic murmur and weak femoral pulses. He was not seen again until the age of 21 years, when he complained of symptoms referrable to a lumbar disc lesion. He was a good athlete, and had never suffered from breathlessness, dysphagia, vertigo, faintness, or intermittent claudication. He suffered occasional bitemporal headaches associated with nausea, but without visual disturbance. He was a thin fit young man, with a high-arched palate but no other manifestation of Marfan's syndrome, and no bodily disproportion. Pulses were depressed in the right carotid artery, weak and delayed in the left subclavian artery, and depressed and delayed in the femoral arteries.

There was a bruit over both carotid arteries, more noticeable on the left, and bruits over the origins of both vertebral arteries, again more conspicuous on the left. The blood pressure measured with a sphygmomanometer was $138 / 80 \mathrm{~mm} . \mathrm{Hg}$ in the right arm, and 118/ $90 \mathrm{~mm}$. $\mathrm{Hg}$ in the left arm. After exercise the blood pressure in the right arm was $150 / 50 \mathrm{~mm}$. Hg. The cardiac impulse was normal. A soft basal ejection systolic murmur and a similar murmur between the shoulder blades were audible. A few small collateral vessels were palpable between the scapulæ. The fundi were normal, and there was no arteriolar tortuosity.

\footnotetext{
* Late House Physician (Clinical Cardiology).
}

Investigations. The electrocardiogram was normal. A chest radiograph showed a small aorta with no aortic knuckle or rib notching. The barium-filled oesophagus was indented by a right-sided aortic arch, and by a vessel above the arch on the left. A retrograde aortogram, by Professor R.E. Steiner, using the Seldinger technique with rapid serial radiographs, revealed (Fig. 1-3) a short moderate coarctation of the aorta, and a right-sided aortic arch passing directly backwards. Arising from the ascending aorta and aortic arch were a dilated left common carotid artery, a hypoplastic right common carotid artery, and a very dilated vessel leading into an otherwise normal right subclavian artery, in that order. The right vertebral artery was large. The left subclavian and left vertebral arteries were not opacified in earlier films, but in later ones (Fig. 4) the large left vertebral artery could be seen filling the left subclavian artery in a retrograde manner. A communication between the left subclavian artery and the aorta was not seen.

The pressure in the ascending aorta was $135 / 70 \mathrm{~mm}$. $\mathrm{Hg}$ and in the thoracic aorta below the coarctation $100 / 70 \mathrm{~mm}$. Hg, a systolic gradient across the coarctation of $35 \mathrm{~mm}$. Hg.

In view of this left "subclavian-steal" pattern, his left arm was exercised to exhaustion in an attempt to provoke symptoms of basilar ischæmia. No such symptoms occurred, nor was there intermittent claudication in the arm.

\section{Discussion}

The "subclavian-steal" syndrome was first reported by Contorni (1960). Reivich et al. (1961) described 2 cases, and produced a similar pattern of flow in 4 dogs by occluding a subclavian artery. Obstruction of the origin of one subclavian artery causes reversed filling from the ipsilateral vertebral artery. Blood flows up the contralateral vertebral, down the ipsilateral vertebral, and into the subclavian artery beyond the obstruction. If there is coexisting inadequacy of the circle of Willis, this "syphoning" of blood from the basilar artery may 


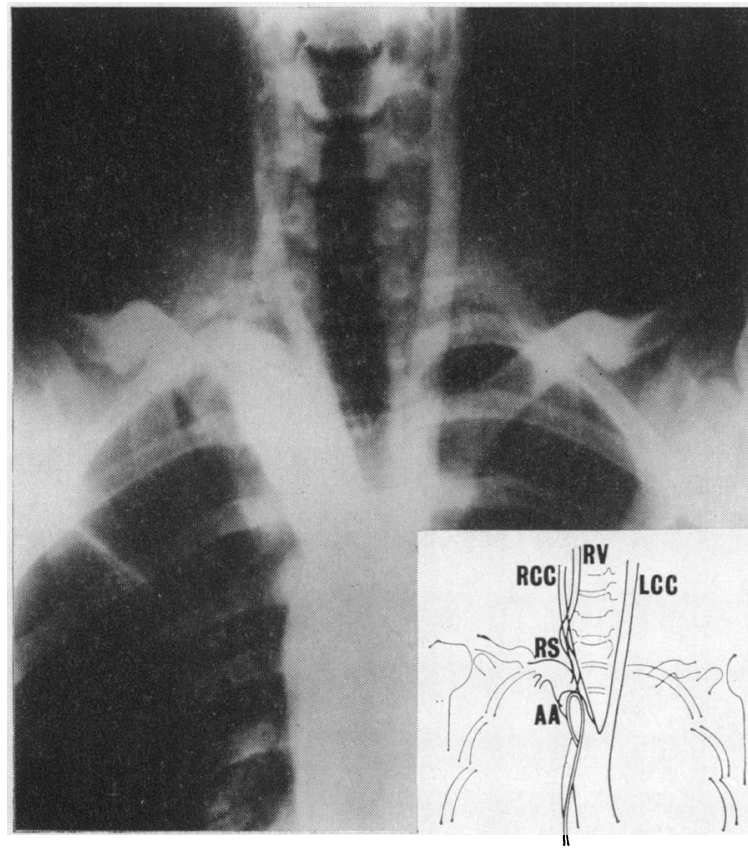

FIG. 1.-Antero-posterior radiograph of arch aortogram showing the major vessels. Early film. Inset: AA, aortic arch; RS, right subclavian artery; RCC, right common carotid artery; LCC, left common carotid artery; RV, right vertebral artery.

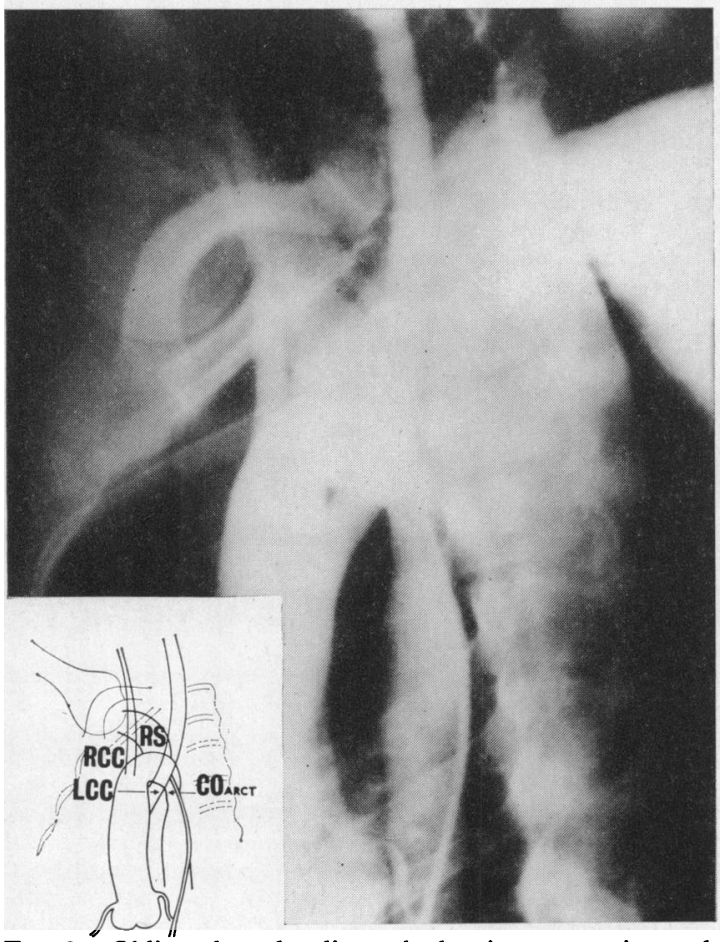

FIG. 3.-Oblique lateral radiograph showing coarctation and major vessels.

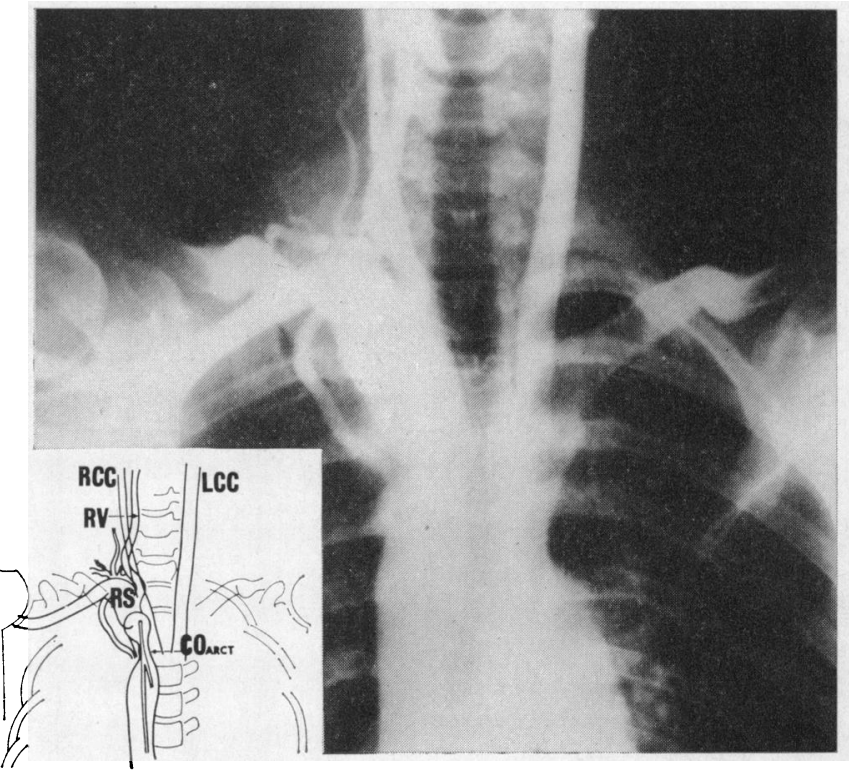

Fig. 2.-As Fig. 1. Slightly later film showing the coarctation. Left vertebral and subclavian arteries not filled. Inset: COARCT, coarctation.

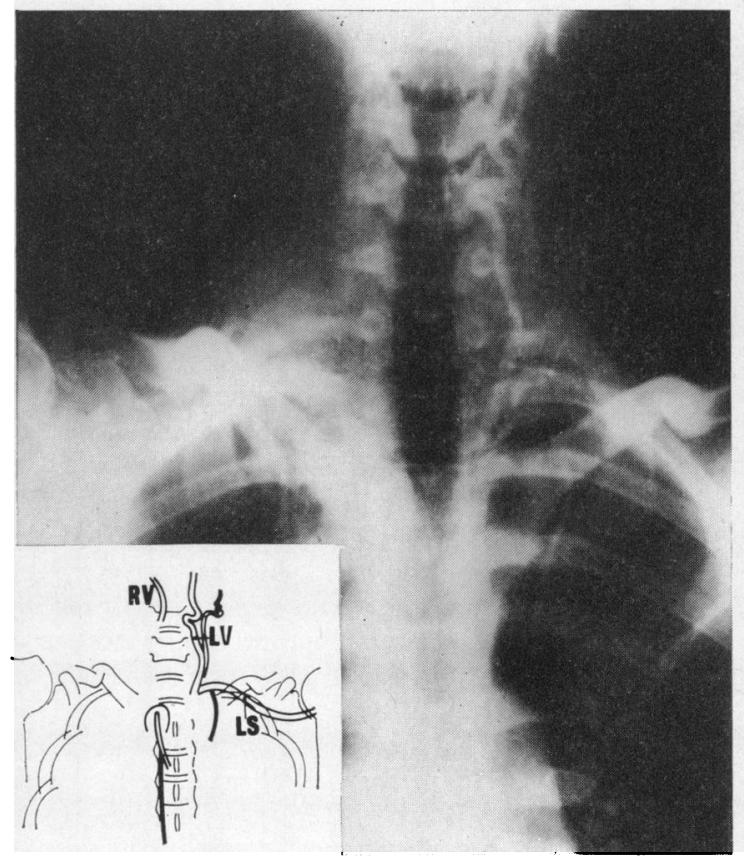

FIG. 4.-As Fig. 1. Late film showing retrograde filling of left vertebral and subclavian arteries. 
produce symptoms of basilar ischæmia. There were no symptoms of this nature in the patient described here, and therefore "subclavian-steal pattern of blood flow" is a better term than "subclavian-steal syndrome". There is no indication for operation at present, but in future years, with developing arteriosclerosis, symptoms may appear, and reconstructive surgery could be considered.

Retrograde brachial arteriography has falsely shown the "subclavian-steal" pattern of blood flow in patients in whom later investigations have proved such a situation not to exist (Curry and Howland, 1964; Shockman, 1964). Toole (1964) emphasized the importance of arch aortography with rapid serial radiographs in the investigation of these patients, for only in this way can the pressures be equalized in all the arch vessels, and the simultaneous flow of contrast medium in each vessel be observed.

The multiple congenital anomalies of the aortic arch vessels in this patient, and the absence of evidence of an arteritis or arteriosclerosis, indicate that the pattern of blood flow is caused by a congenital anomaly of the left subclavian artery. There may be stenosis or absence of the origin of the vessel from the aorta, or the vessel may arise from below the coarctation. Grollman and Horns (1964) reported the latter situation in a man of 43 years, in whom the right subclavian artery had an anomalous origin below a coarctation. They also referred to a report published in Portugal of a patient in whom the left subclavian artery arose below a coarctation (Vianna et al., 1961): an arch aortogram revealed the "subclavian-steal" pattern of blood flow filling the aorta below the coarctation. The filling pressure below the coarctation in these cases must be less than the retrograde filling pressure from the left vertebral artery, which is supplied from above the coarctation.

In addition to reporting this pattern of blood flow due to congenital atresia of the subclavian artery, Massumi (1963) drew attention to a similar situation which may be created by the surgeon. When a Blalock-Taussig shunt is opened, if the subclavian artery is ligated proximal to the origin of the vertebral artery, the subclavian artery may be filled by retrograde flow from the ipsilateral vertebral artery. Reivich et al. (1961) emphasized the importance of ligating the appropriate vertebral artery separately, and suggested pre-operative aortography to determine whether the contralateral vertebral artery appeared adequate to maintain basilar circulation.

An alternative collateral circulation to the classic "subclavian-steal" pattern of blood flow has been demonstrated by Bosniak (1964). This is another way in which blood may be syphoned from the intracranial circulation to bypass a proximal subclavian artery obstruction, through a plexus formed from the occipital branch of the external carotid artery, muscular branches of the vertebral artery, and the thyrocervical and costocervical trunks of the subclavian artery. Bosniak (1964) described one patient with bilateral congenital aplasia of the proximal subclavian arteries, in whom the distal portions of these arteries were supplied by this cervical arterial collateral network.

\section{Summary}

The case is reported of a man of 21 years with coarctation of the aorta and multiple congenital aortic arch abnormalities. A congenital anomaly of the left subclavian artery caused retrograde filling of the left subclavian artery from the left vertebral artery, the so-called "subclavian-steal" pattern of blood flow. Three similar cases and one variant of this rare congenital pattern of blood flow have been previously reported. The mechanism of blood flow in these cases is discussed, and the possibility of creating the situation in a Blalock-Taussig shunt operation is mentioned.

I wish to thank Professor J. F. Goodwin for permission to publish this case. I am grateful to Professor R. E. Steiner who performed the aortogram, and to Professor Goodwin for advice in the preparation of the manuscript.

\section{References}

Bosniak, M. A. (1964). Cervical arterial pathways associated with brachiocephalic occlusive disease. Amer. $\mathcal{f}$. Roentgenol., 91, 1232.

Contorni, L. (1960). Il circolo collaterale vertebro-vertebrale nella obliterazione dell'arteria succlavia alla sua origine. Minerva chir., 15, 268.

Curry, J. L., and Howland, W. J. (1964). Subclavian steal syndrome. Pitfalls in its diagnosis. Amer. F. Roentgenol., 91, 1254.

Grollman, J. H., and Horns, J. W. (1964). The collateral circulation in coarctation of the aorta with a distal subclavian artery. Radiology, 83, 622 .

Massumi, R. A. (1963). The congenital variety of the "subclavian steal" syndrome. Circulation, 28, 1149.

Reivich, M., Holling, H. E., Roberts, B., and Toole, J. F. (1961). Reversal of blood flow through the vertebral artery and its effect on cerebral circulation. New Engl. f. Med., 265, 878.

Shockman, A. T. (1964). Retrograde vertebral artery flow as an artefact of technique. Amer. $\mathcal{f}$. Roentgenol., 91, 1258.

Toole, J. F. (1964). Reversed vertebral artery flow and cerebral vascular insufficiency. Ann. intern. Med., 61, 159.

Vianna, F. C., Borges, S., Bocanegra, J., Guinarães, R. de F., Gallucci, C., Yunis, C. B., Algranti, N., Balbo, R., Casanova, R., and Forte, V. (1961). Left aortic coarctation with post-coarctation subclavian collateral circulation through the vertebral arteries. Arch. bras. Cardiol., 14, 261. (In Portuguese). Quoted by Grollman and Horns (1964). 